\title{
A ENCRUZILHADA POÉTICA DA CIA BIRUTA DE TEATRO EM NOTÍCIAS DO DILÚVIO - UM CANTO A CANUDOS
}

\author{
Antonio Veronaldo Martins ${ }^{1}$ \\ Camila Rodrigues da Silva ${ }^{2}$ \\ Cristiane Crispim Bezerra ${ }^{3}$ \\ Luis Osete Ribeiro Carvalho ${ }^{4}$
}

\begin{abstract}
RESUMO
Este relato de experiência tem como objetivo discorrer sobre a encenação Notícias do Dilúvio um canto a Canudos, apresentada pela Cia Biruta de Teatro, grupo teatral de Petrolina-PE, no projeto Cena agora, realizado pelo Núcleo de Artes Cênicas do Itaú Cultural nos meses de abril e maio de 2021. De início, são abordadas as encruzilhadas que amparam e promovem as narrativas poéticas dos 13 anos de trajetória da Cia, enfatizando, na sequência, as fontes, as oralituras e os signos presentes em Notícias do Dilúvio, sempre em interlocução com referenciais teóricos que introduzem novas percepções aos caminhos artísticos elaboradas nessa obra. Este relato segue o fluxo da própria construção dos trabalhos da Biruta, em que se cruzam reflexões teóricas, vivências em práticas culturais, registros históricos e toda a ampla rede de referenciais que contribuem para tecer as encruzilhadas poéticas do grupo.
\end{abstract}

Palavras-chave: Cia Biruta. Notícias do Dilúvio. Mulheres de Belo Monte. Práticas Culturais. Encruzilhada.

\section{THE POETIC CROSSROADS OF CIA BIRUTA DE TEATRO IN NOTÍCIAS DO DILÚVIO - UM CANTO A CANUDOS}

\footnotetext{
${ }^{1}$ Diretor, ator, produtor e co-fundador da Cia Biruta de Teatro, onde desenvolve pesquisas sobre o ator ribeirinho e suas culturas no médio São Francisco, percurso do Rio São Francisco em Pernambuco. Participou da ISTA - International School of Theatre Antropology, em Albino Italy no ano 2016, realizado pelo Odin Teatret (DK). E-mail: veronaldomartins@gmail.com.

${ }^{2}$ Graduanda do curso de Licenciatura em Língua Portuguesa com habilitação em Língua Espanhola pela Universidade de Pernambuco, campus Petrolina. É atriz-pesquisadora e produtora cultural na Cia Biruta de Teatro. No audiovisual, atua como diretora, editora, cinegrafista e fotógrafa da Abajur Soluções. Email: camilaarodrigues4@gmail.com.
}

3 Atriz, pesquisadora, produtora cultural, diretora e arte-educadora. Licenciada em Artes Visuais pela UNIVASF, pós-graduada em Dança Educacional e Artes Cênicas pela Censupeg e mestranda em Educação, Cultura e Territórios Semiáridos pelo PPGESA/UNEB. Co-fundadora da Cia Biruta de Teatro, grupo em onde desenvolve ações de formação e pesquisa artísticas na periferia e a partir de vivências dos processos e práticas populares de resistência das margens do Rio São Francisco. Professora da rede pública do Estado da Bahia. E-mail: cristiane.crispim@outlook.com.

${ }^{4}$ Mestre em Educação, Cultura e Territórios Semiáridos pela Universidade do Estado da Bahia (UNEB); Jornalista do Instituto Federal do Sertão Pernambucano (IFSertãoPE); Graduado em Comunicação Social/Jornalismo em Multimeios pela UNEB, em Juazeiro-BA; Integrante do Núcleo de Teatro do Sesc Petrolina entre 2009 e 2020. Colabora na dramaturgia de Notícias do Dilúvio - um canto a Canudos. Email:luisosete@gmail.com. 


\begin{abstract}
This experience report aims to discuss the staging Notícias do Dilúvio - um canto a Canudos, presented by Cia Biruta de Teatro, a theater group from Petrolina-PE, in the project Cena Agora, performed by the Núcleo de Artes Cênicas of Itaú Cultural in the months of April and May 2021. Initially, the crossroads that support and promote the poetic narratives of the Company's 13-year history are addressed, in sequence, emphasizing the sources, oralituras and signs present in Notícias do Dilúvio, always in dialogue with theoretical references that introduce new perceptions to the artistic paths elaborated in this work. This report follows the flow of the construction of Biruta's works, in which theoretical reflections, experiences in cultural practices, historical records and the entire wide network of references that contribute to weaving the poetic crossroads of the group intersect.
\end{abstract}

Keywords: Cia Biruta. Flood News. Women of Belo Monte. Cultural Practices. Crossroads.

\title{
LA ENCRUCIJADA POÉTICA DE LA CIA BIRUTA DE TEATRO EN NOTÍCIAS DO DILÚVIO - UM CANTO A CANUDOS
}

\section{RESUMEN}

Este informe de experiencia tiene como objetivo discutir la puesta en escena "Notícias do Dilúvio - Um canto a Canudos", presentada por la Cia Biruta de Teatro, un grupo teatral de Petrolina-PE, en el proyecto Cena Agora, realizado por el Núcleo de Artes Cênicas del Itaú Cultural en los meses abril y mayo de 2021. Inicialmente, se abordan las encrucijadas que sustentan y promueven las narrativas poéticas de la trayectoria de 13 años de la Cia, destacando las fuentes, em secuencia, oralituras y signos presentes en Notícias do Dilúvio, siempre en interlocución con referencias teóricas que introducen nuevas percepciones a los caminos artísticos elaborados en esta obra. Este informe sigue el flujo de la propia construcción de las obras de la Biruta, en que se cruzan reflexiones teóricas, vivencias en practicas culturales, registros históricos y toda la amplia red de referencias que contribuyen a tener las encrucijadas poéticas del grupo.

Palabras clave: Cia Biruta. Notícias do Dilúvio. Mujeres de Belo Monte. Practicas culturales. Encrucijada.

\section{Introdução}

Para pisar um território sagrado é preciso pedir Agô ${ }^{5}$. É só a partir da licença dada pelas/os ancestrais que acontece a vivência, o mergulho, o reconhecimento, a transmissão do conhecimento que se incorpora como experiência. Depois de muitas licenças recebidas ao longo dos últimos 13 anos, a Cia Biruta de Teatro vem aqui pedir Agô às ancestralidades que atravessam a sua história para partilhar a cada leitora/leitor

\footnotetext{
${ }^{5}$ Agô é uma palavra em Yorubá que expressa um pedido de licença, dar passagem, espaço para algo passar ou alguém. Embora a grafia, em Yorubá, seja Àgò, resolvemos adotar a versão aportuguesada, que circula com mais frequência entre a população brasileira.
} 
os caminhos de uma encruzilhada interdimensional, que se espraia da sola dos pés ao chakra coronário e é, em larga medida, como o sertão de Guimarães Rosa (1986): sem lugar, em toda parte, do tamanho do mundo e dentro da gente.

Em todas essas caminhadas, aprendemos ${ }^{6}$ que olhar para dentro requer, sobretudo, reconhecer que dentro, ao lado, em cima, em volta, abaixo de nós moram muitas/os, sem as/os quais é impossível dar qualquer passo. Por isso, não é fácil revelar de onde falamos e como aprendemos o que desejamos comunicar. Muitas experiências que nos cruzam são irreveláveis, intransmissíveis, únicas, singulares e irrepetíveis. Tal constatação, entretanto, não nos paralisa, ao contrário, impulsiona a tecer um novo aprendizado: o de bordar o relato do que é possível transformar em encenação.

Ao demonstrar as teias dessa tessitura encenada, buscaremos travar alguns diálogos com os referenciais teóricos e práticos que nos ajudam a entender as engrenagens dos universos em que estamos inseridos. Entendemos, com Maximiliano López (2011), que um conceito é uma constelação integrada de jogos de verdade, relações de poder e formas de subjetividade. É, portanto, multiverso e polissêmico, ainda mais quando consideramos as avenidas identitárias da interseccionalidade (AKOTIRENE, 2018). Os conceitos, além disso, guardam o seu próprio segredo, que, em relação à arte (secreta) da atuação, mestres como Eugenio Barba (1995) nos ajudam a trilhar e iluminar caminhos.

Assim, nessa encruzilhada poética em torno do experimento híbrido ${ }^{7}$ Notícias do $^{2}$ Dilúvio alguns conceitos serão mais detidamente analisados. Para pensarmos os ambientes de memórias que temos percorrido, na busca por ampliarmos nosso repertório com as performances da oralidade, as práticas rituais, as cerimônias, os

\footnotetext{
${ }^{6}$ Embora um dos autores deste relato de experiência não seja integrante da Cia Biruta de Teatro, optamos pela primeira pessoa do plural. Com isso, nos aproximamos mais de quem lê e destacamos a vinculação histórica do grupo com o trabalho coletivo.
}

\footnotetext{
${ }^{7}$ Notícias do Dilúvio - um canto a Canudos é caracterizado aqui, ao mesmo tempo, como uma encenação e um experimento híbrido. A opção por encenação diz respeito à vinculação essencial com o espaço cênico, que é o ambiente primordial onde a Cia Biruta de Teatro elabora a sua poética. Entretanto, por trazer elementos intrínsecos à linguagem audiovisual, o trabalho apresentado pela Cia no projeto Cena agora se aproxima mais de um experimento híbrido, na encruzilhada entre duas artes: teatro e cinema.
} 
festejos, as caminhadas e as romarias, são fundamentais as noções de tradição oral em Amadou Hampâté Bâ (1980) e encruzilhada e oralitura, presentes nas reflexões de Leda Martins (2003).

Além das ancestralidades e dos referenciais teóricos, pedimos licença neste relato de experiência a quem corporaliza os ensinamentos no labor da cotidianidade e, generosamente, nos transmite o sentido, o valor e o fundamento do pisar de cada passo, regando o solo com sangue, suor e saliva. Nem cabem em palavras as tantas mestras e mestres que encontramos em nossa trajetória, de joelhos em frente ao oratório, de espadas no meio do Reisado, de velas acesas nas romarias, de olhares sérios na frente das marchas, nas horas sagradas de lutas, orações e celebrações, nas ruas, nos rios e nas matas.

A todas essas almas ancestrais, encarnadas e desencarnadas, pedimos Agô e iniciamos, aqui, mais um passo escrito da nossa caminhada.

\section{Cia Biruta de Teatro: uma trajetória de encruzilhadas}

"O ato de caminhar é o movimento imemorial da inquietude", nos diz Eduardo Lalo (p. 34, 2014) assim que abre seu texto Notícias do Dilúvio. E essa inquietude experimentamos na Cia Biruta, que peregrina há 13 anos no território sagrado do teatro com ações nas áreas de produção, criação e formação teatral, tendo como sede a cidade de Petrolina ${ }^{8}$. Os primeiros passos correspondem ao anseio por profissionalização e, mais à frente, desenvolvem-se na busca por imprimir uma identidade a esse trajeto, afirmando-se na concepção de teatro de grupo, relatado por Eugênio Barba (2010) como "o terceiro teatro". Esse termo utilizado por Barba faz referência à ideia de um tipo de teatro presente nas margens e de forma autodidata, em que a dimensão ética e existencial do seu ofício e a vocação sociocultural são bases para o desenvolvimento e a manutenção de grupos que não se inspiram nem no teatro tradicional, nem no de vanguarda. Nesse contexto, o grupo vai encontrando nas suas próprias vivências a

\footnotetext{
${ }^{8}$ Petrolina é um município localizado no estado de Pernambuco, a cerca de $750 \mathrm{~km}$ de Recife. Tem uma população estimada em 350 mil habitantes. É banhada pelo Rio São Francisco e faz divisa com o município de Juazeiro (BA). Ambas as cidades compõem a Região Administrativa Integrada de Desenvolvimento do Polo Petrolina e Juazeiro, a maior RIDE/região metropolitana do interior do Nordeste. Marcada pela presença oligárquica e coronelística, Petrolina é dominada politicamente há mais de sete décadas pela família Coelho.
} 
possibilidade de um fazer teatral que busca a sua independência, construindo coletivamente uma forma de ofício e resistência.

A partir de 2012, quatro anos após a sua fundação, o grupo iniciava discussões internas que propunham a elaboração de procedimentos de investigação do corpo que dialogassem com a pergunta "Quem eu sou", incluindo: percursos genealógicos, culturais, sociais e históricos. Essas discussões culminaram na elaboração e execução do projeto de pesquisa e experimentação cênica Cenas Ribeirinhas (2014-2016), que percorreu comunidades das cidades pernambucanas do sertão do São Francisco. Como força motriz artístico-pedagógica, as cenas foram criadas tendo como ponto de partida a elaboração de partituras físicas desenvolvidas a partir de "motes" poéticos, frases, metáforas, inspirados nas paisagens, histórias, sonoridades e técnicas de corpo de festas e danças das práticas populares das comunidades mapeadas pela pesquisa.

As práticas populares de comunidades quilombolas, indígenas e ribeirinhas dos sertões passam a fazer parte dos processos criativos do grupo não apenas como tema, mas como procedimentos, meios de encontrar as presenças de suas atrizes e atores. $\mathrm{O}$ exercício da presença em cena advém da necessidade de retomar a presença que socialmente foi alienada, negada de autonomia enquanto descendentes de corpos arrancados de seus coletivos, de suas vivências comunitárias, para as periferias urbanas, em um processo violento de desterritorialização e de exploração de mão de obra.

A encruzilhada é um conceito que fala da experiência negra de mestiçagens e hibridismos na diáspora brasileira sobre o qual Leda Maria Martins escreve:

A cultura negra também é, epistemologicamente, o lugar das encruzilhadas. O tecido cultural brasileiro, por exemplo, deriva-se dos cruzamentos de diferentes culturas e sistemas simbólicos, africanos, europeus, indígenas e, mais recentemente, orientais. (...) A noção de encruzilhada, utilizada como operador conceitual, oferece-nos a possibilidade de interpretação do trânsito sistêmico e epistêmico que emergem dos processos inter e transculturais, nos quais se confrontam e se entrecruzam, nem sempre amistosamente, práticas performáticas, concepções e cosmovisões, princípios e metafísicos, saberes diversos, enfim. (MARTINS, p. 69, 2003)

Quando pensamos nas encruzilhadas, pensamos nas rotas de experiências negras e indígenas no sertão do São Francisco, que são, em grande parte, rotas de fugas, rememoradas em danças do São Gonçalo hoje dançadas em todas as comunidades da 
beira do Rio São Francisco. São dessas memórias de resistência, escritas em passos, palmas e cantos que invocamos a ancestralidade que nos faz gente, antes de atores e atrizes. São nos nossos corpos, de mulheres, de pessoas negras e pardas, descendentes de indígenas que ocupam a periferia de uma região rurbana - território em que se desenvolvem estruturas rurais e urbanas - e ribeirinha que nossas encruzilhadas abrem caminhos para as poéticas do grupo. Encruzilhadas identitárias que marcam corpos situados à margem e que encontram na arte um eixo, um caminho em que é possível perspectivar suas presenças de maneira afirmativa.

A bagagem pedagógica desses trajetos é compartilhada com a comunidade periférica onde o grupo se insere, através do Núcleo Biruta de Teatro. É vivido um processo artístico-pedagógico que permite uma troca de saberes e de novas encruzas de experiências, tornando o espaço favorável para a elaboração conjunta de um percurso formativo que compreende as potencialidades surgidas no campo da educação nãoformal enquanto espaço de construção da cidadania no território que ocupa. Desse modo, a Cia Biruta, em suas pesquisas, contribui para o fortalecimento do sentido de comunidade, incentivando a (re)afirmação de identidades que se formam em coletivo.

"O grupo de teatro é um quilombo", nos falou Eugênio Barba em conversa informal na realização do evento Pontes Flutuantes, produzido pela Cia Biruta. Sua afirmação, de um observador das mais diversas culturas dentro da cultura do teatro e de quem criou, junto com companheiras e companheiros do Odin Teatret, a tradição de teatro grupo, refere-se à forma de organização dos grupos enquanto resistência a modos de produção excludentes, seja de um teatro comercial, ou de um teatro institucional, ligado às universidades ou ao controle direto do Estado.

Na pesquisa Cenas Ribeirinhas, vimos que os quilombos, no sertão do São Francisco, se relacionam com os territórios indígenas, de modo que alguns territórios poderiam ser demarcados com ambas as identidades, por conter traços de presença e cultura tanto indígena, como quilombola. As histórias de acolhimento, por comunidades indígenas, de negros fugidos são inúmeras. Encontrar as práticas populares do sertão do São Francisco, suas formações e suas vivências comunitárias norteiam o grupo na busca pela identidade enquanto artistas de teatro no sentido de empreender retomadas de cosmovisões que foram apagadas e silenciadas, que resultaram nas alienações impostas 
aos artistas das periferias. A experiência do quilombo é étnica e racial, mas, sobretudo, territorial.

O teatro é o nosso território, a nossa terra sagrada. Nele desenvolvemos diálogos com as mais diversas culturas, mas onde fazemos teatro é o que somos e temos direito a esse fazer. As histórias nos conectam às memórias de ancestralidades que cruzam o intercâmbio elaborado pelo grupo entre a pergunta "quem eu sou" e sua formação profissional. Belo Monte é também um quilombo e navegou até a gente pelos rios Vaza Barris e São Francisco, entrecruzando-se com a história de formação do Quilombo da Mata de São José, em Orocó, através da pesquisa Cenas Ribeirinhas, que se torna o nosso horizonte de repertório sensível, visões de mundo e encruzilhadas poéticas.

\section{A encruzilhada poética da Cia Biruta de Teatro em Notícias do Dilúvio - um canto a Canudos}

Como foi possível perceber na exposição dos caminhos da Cia Biruta de Teatro, a encruzilhada é o espaçotempo que oferece as diversas possibilidades de pesquisa e encenação do grupo. É onde as referências se encontram, se atravessam, se misturam e se espalham. É também onde que deitamos nossa esteira e sentamos o chão do nosso pertencimento, e partilhamos as nossas experiências, brindamos os nossos saberes, louvamos os nossos sentidos, renovamos o nosso Axé ${ }^{10}$.

Quando o Núcleo de Artes Cênicas do Itaú Cultural convidou a Cia Biruta para o projeto Cena agora, indicando como tema Encruzilhada Nordeste(s): (contra)narrativas poéticas e solicitando a criação de uma apresentação teatral de 15 minutos para ser veiculada na plataforma on-line Zoom, se abriu uma nova

\footnotetext{
${ }^{9} \mathrm{Na}$ escrita deste relato de experiência, resolvemos adotar a nomeação de Belo Monte para o território habitado por Antônio Conselheiro, Beatinho, Maria Francisca, Benta e tantas mulheres, homens, idosos e crianças, peregrinas/os que ali aportaram em 1893. Afinal, essa foi a nomeação escolhida pelos/as novos/as moradores/as, ao vislumbrarem a beleza das elevações geográficas que circundam a localidade. Reconhecemos, porém, que o título da encenação traz o nome Canudos e justificamos essa escolha pelo fato de a maioria esmagadora da historiografia imprimir essa denominação, criando uma dificuldade de associação do nome Belo Monte àquela experiência sertaneja que perdurou fisicamente até 1897 . Ao longo da encenação, as próprias personagens variam a nomeação entre Canudos e Belo Monte, com predominância desta última referência.
}

10 Axé ou Àșẹ é uma palavra em Yorubá que significa energia, poder, força. 
encruzilhada. O espaçotempo da possibilidade que emergiu para o coletivo se transmutou na oportunidade de mostrar vestígios de uma transgressão da historiografia oficial em torno da experiência do Belo Monte que vem sendo gestada desde 2018.

Assim, ao lado de uma ampla bibliografia disponível, que marginalmente situa a participação das mulheres no cotidiano belomontense e na luta contra a invasão do exército, se cruzam referências a orações de proteção e defesa, cantigas específicas do Reisado e ainda não registradas em livros, objetos ritualísticos como o oratório e os exvotos, iconografias contra hegemônicas e uma série de outras fontes pouco discutidas pela historiografia em torno de uma das mais importantes experiências de resistência popular do Brasil.

Essas fontes se entrelaçam, inclusive, com aportes acadêmicos, como o artigo Notícias do Dilúvio, do escritor porto-riquenho Eduardo Lalo (2014), que dá nome à nossa encenação. Em uma poética encruzilhada, Lalo reúne a poetisa argentina Alejandra Pizarnik, relatos míticos sobre a inundação universal, além de histórias e cantos de um dos últimos povos nômades do mundo: os selk'nam, para falar sobre o empenho em converter o caminho em leitura, o trajeto em relato, e construir a memória e o conhecimento.

Desde a primeira cena do nosso experimento híbrido, buscamos também trazer Notícias do Dilúvio. Na imagem inicial, as personagens Das Dores (Cristiane Crispim) e Dos Anjos (Camila Rodrigues) aparecem com coroas e espadas do Reisado em uma movimentada avenida de Petrolina e, dali, passam a entoar uma oração muito frequente nas Novenas pelas Almas, enquanto percorrem outros espaços urbanos e rurais do município entre passos de dança, caminhadas, correrias e pausas para mostrar fotografias da iconografia belomontense. 
Figura 1 - Das Dores e Dos Anjos na abertura de Notícias do Dilúvio - um canto a Canudos

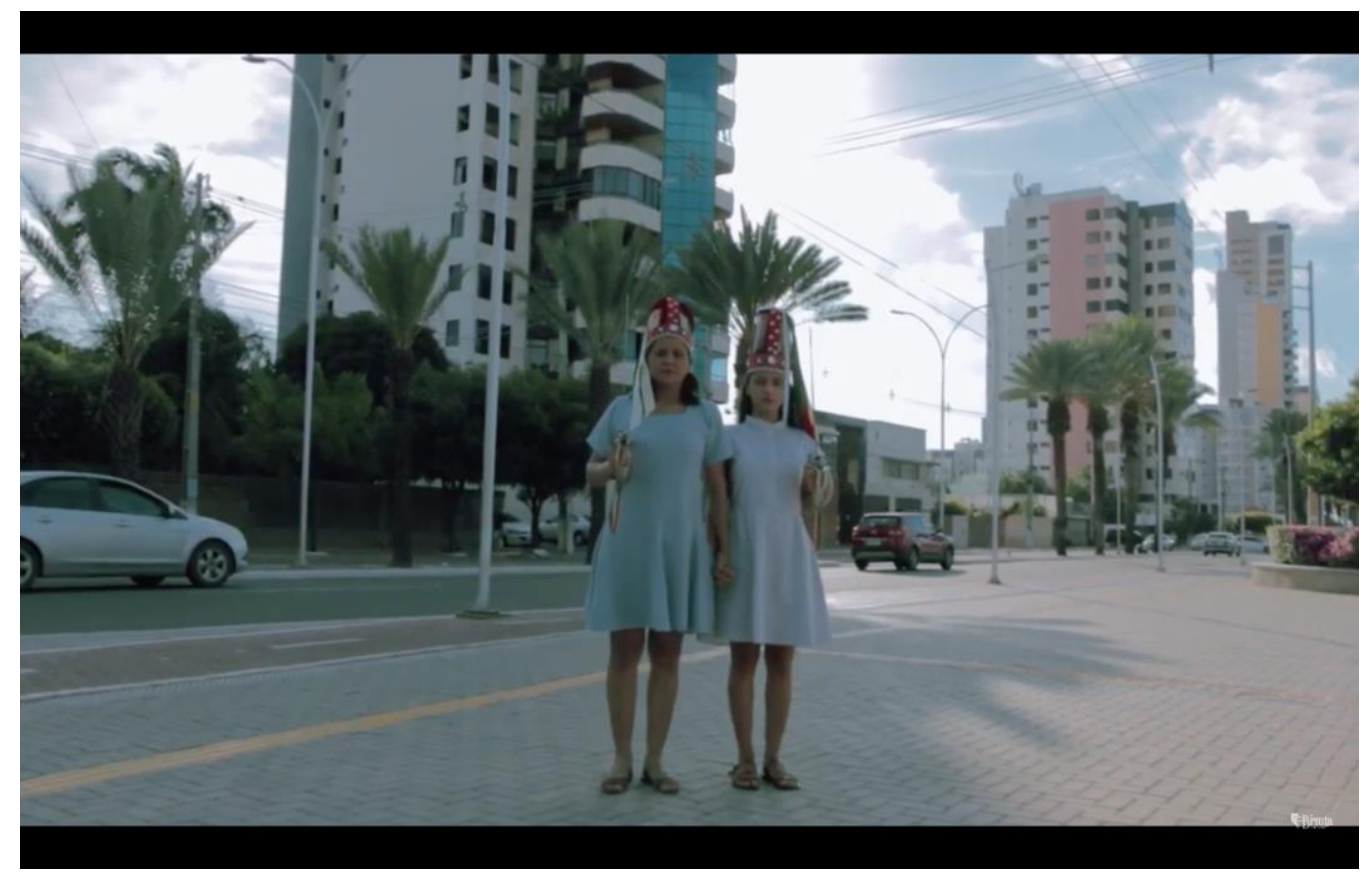

Fonte: Canal da Cia Biruta de Teatro no YouTube. Fotografia: Fernando Pereira

É com Leda Martins (2003) que identificamos o quanto os corpos expostos nas fotos de Flávio de Barros estão presentificados nas diversas performances rituais, cerimônias e festejos que transmitem e instituem saberes estéticos, filosóficos, metafísicos, religiosos, científicos e tecnológicos nos povos habitantes do sertão brasileiro. É essa textualidade herdada dos domínios de linguagem e dos modos de apreender e figurar o real legados pelos povos africanos e indígenas que nos interessa encenar e escrever.

Por isso, a Cia Biruta compreende que, tão importante quanto encontrar vestígios da presença de mulheres na experiência do Belo Monte, nas tão breves e lacônicas referências encontradas na bibliografia consultada, é vivenciar a permanência dos saberes que religam performances rituais da atualidade com aquelas praticadas durante a existência física de Belo Monte, restituídas, reincorporadas, transcriadas e revividas sob o signo da reminiscência. "A esses gestos, a essas inscrições e palimpsestos performáticos, grafados pela voz e pelo corpo", Leda Martins (2003) chama de oralitura. 
Ao longo do processo criativo de Notícias do Dilúvio, foi possível encontrar oralitura, isto é, "traço residual, estilístico, mnemônico, culturalmente constituinte, inscrito na grafia do corpo em movimento e na vocalidade" (MARTINS, 2003) de práticas rituais como a Romaria de Nossa Senhora das Candeias e o Reisado, em Juazeiro do Norte (CE), as Alimentadeiras das Almas, em Juazeiro (BA), o Reisado no Quilombo Mata de São José, em Orocó (PE), as Caixeiras do Divino Espírito Santo, em Alcântara (MA) e todo o acúmulo da Cia Biruta nesses anos de montagens, com o acompanhamento de diversas performances da oralidade e práticas rituais no submédio São Francisco, como o Samba de Reis, o Capim Lelê, a Roda de São Gonçalo, o Novenário e as Festas de Caboclo.

Tais performances rituais inscrevem no corpo as memórias de um povo predominante oral e gestual, como são os povos indígenas e quilombolas, e assim matizam o que Leda Martins (2003, p. 74) chama de "a primazia do movimento ancestral nas curvas de uma temporalidade espiralada, na qual os eventos, desvestidos de uma cronologia linear, estão em processo de uma perene transformação". É esse tempo espiralar que buscamos na encenação, na perene transformação das personagens, em seus confrontos estéticos com o tempo devastador da modernidade e seus signos de desenvolvimento e progresso.

Todas essas referências dialogam com o campo da tradição oral, descrita pelo escritor malinês Amadou Hampâté Bâ (1980) como a grande escala da vida, que conjuga ao mesmo tempo religião, conhecimento, ciência natural, iniciação à arte, história, divertimento e recreação. Em nossas andanças pelas comunidades, percebemos o quanto as mestras e mestres das práticas rituais retêm os pormenores de cada uma dessas dimensões da vida cotidiana, preservando e restabelecendo nas brincadeiras, nas rezas e no labor o equilíbrio das forças do qual depende a harmonia do mundo material e espiritual. Um dos trechos da oração inicial de Notícias do Dilúvio expressa o quanto as palavras sagradas clamam pela harmonia material:

Suplico a Vós meu Jesus Cristo, Salvador do mundo, que lhes devolvais a luz perdida e também que interceda a Deus Pai por todos nós, pecadores que estamos aqui, vivos, sobrevivendo a tantos genocídios, que derrame Senhor a tua bênção, a tua Piedade, a tua Misericórdia, nos livrando das horas más, dos perigos e dos inimigos. (NOTÍ́CIAS, 2021) 
Essa evocação direcionada ao mundo dos espíritos atualiza uma oração transmitida pela cadeia de ancestrais da religiosidade popular ao adicionar na intercessão pedida a Deus Pai aos pecadores vivos a necessidade de sobreviver aos genocídios em curso na história brasileira, entre os quais, sem dúvida alguma, estão o extermínio de Belo Monte e a vigente política de morte em torno da pandemia do novo coronavírus ${ }^{11}$. Esse tipo de atualização está presente também na "alucinação" da personagem Dos Anjos, quando expressa uma visagem que teve da luta empreendida no Belo Monte "contra o dragão e suas dez mil bocas de fogo com seus filhos paridos de ódio e ganância" (NOTÍCIAS, 2021):

Era real demais! O rosto do povo iluminado pela revolta reclamava justiça. Gritos de vitórias coloriam suas almas, aqueciam seus corações. E, com seus maracás nas mãos, rezavam e entoavam cantos de esperanças, cantando e dançando na maior alegria do mundo para saudar aqueles que chegavam a Belo Monte. Em uma das chamas, Maria da Guerra dizia que é preciso resistir em todos os lugares e falar com o nosso corpo. Que nossos passos vêm de longe, de outros mares e de outras marés, das nossas ancestrais e de outros quilombos. E no fogo que ardia em minha frente veio até mim a força de todas as mulheres que construíram a nossa história.

Alguns trechos dessa paisagem onírica evocada por Dona Anjos nos remete ao último discurso proferido pela socióloga e política brasileira Marielle Franco, assassinada junto de seu motorista, Anderson Gomes, no dia 14 de março de 2018. Minutos antes de ser morta com quatro tiros na cabeça, Marielle estava participando do debate Jovens Negras Movendo as Estruturas, organizado pelo seu partido, o Partido Socialismo e Liberdade (PSOL), na Casa das Pretas, espaço coletivo de mulheres negras na Lapa, no centro do Rio de Janeiro. Ali, entre outras palavras, ela disse que é preciso resistir em todos os lugares e se reconhecer na luta, com as mulheres que vão nos

\footnotetext{
${ }^{11}$ No momento da escrita deste relato de experiência, os números de mortes pela Covid-19 se aproximam, no Brasil, da assombrosa marca de 500 mil. Por outro lado, a vacinação, principal via de prevenção da contaminação pelo vírus, foi desestimulada pelo Governo Federal ao longo de 2020, provocando a atual lentidão em imunizar a população brasileira. Além disso, o presidente da república menosprezou os efeitos da pandemia, promoveu aglomerações, se contrapôs publicamente aos únicos métodos disponíveis para evitar a proliferação do novo coronavírus, estimulou o uso de medicamentos sem eficácia comprovada e que podem até piorar os casos de Covid-19 e se desresponsabilizou de assumir o enfretamento à pandemia e salvaguardar vidas, assumindo a alcunha, para uma parcela da sociedade brasileira, de Genocida.
} 
ajudando a encontrar quem a gente é. A força desse último depoimento de Marielle dialoga, ao mesmo tempo, com referências a Dandara, no livro As Lendas de Dandara, de Jarid Arraes (2016) e às mulheres que lutaram em Belo Monte, como Maria Rita e Maria da Guerra, presentes em breves trechos da obra Canudos: a guerra social, de Edmundo Moniz (1987).

Essa encruzilhada de vozes é uma das vertentes mais fortes do processo criativo de Notícias do Dilúvio e está presente também na cena da prisioneira degolada, quando a personagem Das Dores, após um angustiante interrogatório, une as mulheres prisioneiras em Belo Monte, registradas por Euclides da Cunha (2016) e Manoel Benício (1997), com mulheres presas, mortas e desaparecidas na Guerrilha do Araguaia $^{12}$, divulgadas por Hugo Studart (2006):

Meu marido foi morto por um lote de soldados quando saía; o mesmo tiro quebrou o braço do meu filho de colo... Eu fiquei lá, estatelada, não vi nada... este sangue aqui na minha manga é do meu filho, o que eu queria era ficar lá também, morta... Aquele sangue era meu. O meu filho, o sangue, a fé, a saudade. E agora de nada me valem essas perguntas. E agora eu não tenho mais medo de nada. Vocês estão perdidos. Vocês não vão voltar nunca. Vão ficar por aí tateando à toa, sem sentido, sem luz, sem sombra, sem som, sem tempo, sem memória, sem paz, sem amor, sem justiça, sem liberdade. Calar-me? Era o que faltava. Querem tirar a minha voz também? Pois é fácil, cortem o meu pescoço, como tem feito com os desgraçados que vieram pedir socorro. Cortem porque enquanto eu puder falar vou excomungá-los como filhos do inferno que são. Enquanto eu puder gritar contarei ao mundo a covardia, a bestialidade, que se é degolar prisioneiros, mulheres e crianças. Se apoderaram de nossas casas, dos nossos potes, das nossas roupas, do nosso feijão, de nossa farinha, de nosso milho, de tudo quanto tínhamos! Não estão satisfeitos?! Não temos mais onde carregar um pingo de água, nem o que comer. Tocaram fogo em nossas roças, mataram os nossos filhos e maridos. Querem o que mais agora? A nós, mulheres? Não me toquem! Quer ver uma mulher brigar, me dá sua arma, seu covarde. Vocês vão me matar agora é? É aqui que eu vou morrer? Pois vocês vão ter que me matar de frente! Vocês vão ter que me matar olhando bem dentro do meu ódio! O povo é imortal! Viva a Belo Monte! (NOTíCIAS, 2021)

\footnotetext{
12 A Guerrilha do Araguaia foi um movimento de luta armada organizado pelo Partido Comunista do Brasil (PCdoB) entre fins da década de 1960 e a primeira metade da década de 1970, nas margens do rio Araguaia, nos estados do Pará e Tocantins. Atualmente, dezenas de guerrilheiros do Araguaia figuram na lista de desaparecidos políticos do regime militar.
} 
Figura 2 - Das Dores na cena da prisioneira degolada em Notícias do Dilúvio - um canto a Canudos

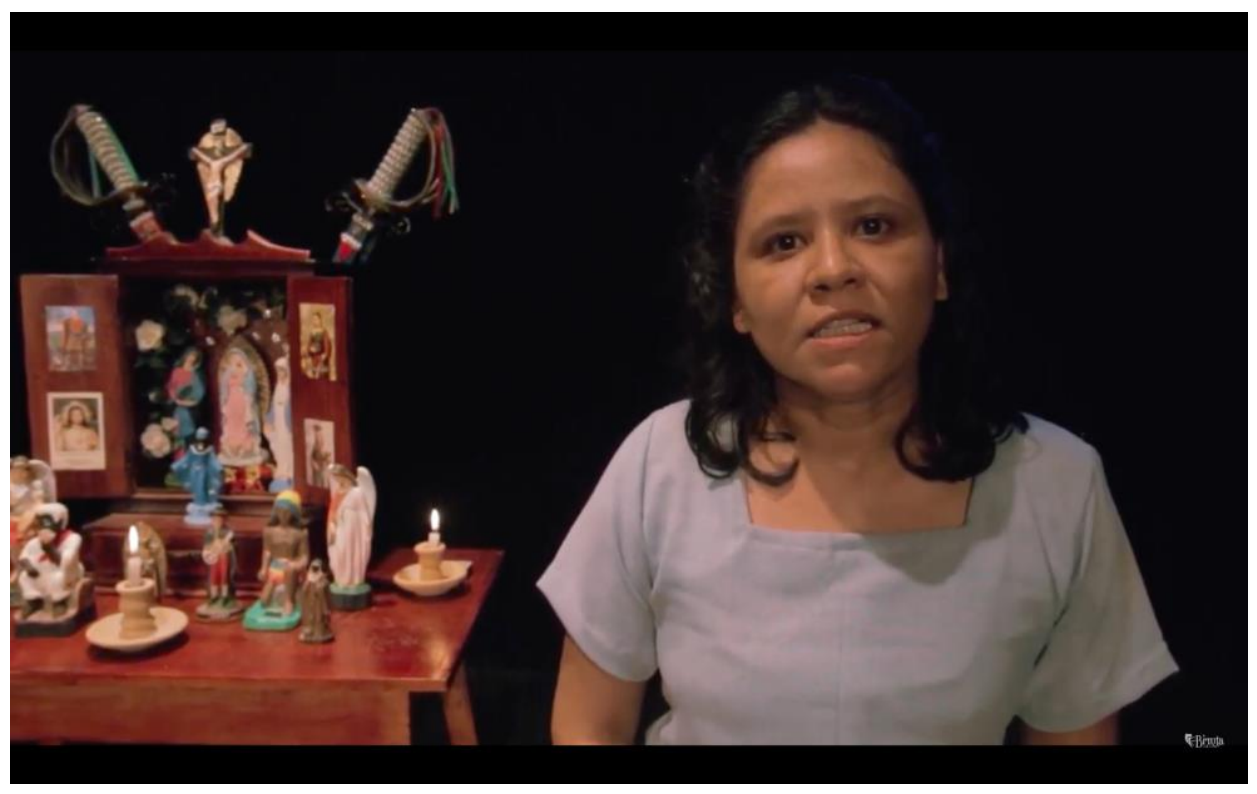

Fonte: Canal da Cia Biruta de Teatro no YouTube. Fotografia: Fernando Pereira

Como em toda a dramaturgia de Notícias do Dilúvio, há também a nossa participação inventiva na evocação dessa história, com inserções que reforçam os sentidos que queremos imprimir ao enredo da encenação. Afinal, nessa encruzilhada poética, as vozes que carregamos também ecoam "versos perplexos, com rimas de sangue e fome", como escreve Conceição Evaristo (2017, p. 24-25) no poema Vozesmulheres, e segue:

A voz de minha filha recolhe todas as nossas vozes recolhe em si as vozes mudas caladas engasgadas nas gargantas.

A voz de minha filha recolhe em si a fala e $o$ ato. O ontem - o hoje - o agora. $\mathrm{Na}$ voz de minha filha 
se fará ouvir a ressonância

O eco da vida-liberdade.

Essas personagens são, de certa maneira, as nossas filhas, e, a partir delas, fazemos ouvir a ressonância dos ecos de vida-liberdade que acalentamos a cada passo da nossa caminhada artística. Das Dores e Dos Anjos são também as nossas mães, avós, bisavós, ancestrais. São a permanência da memória seletiva do conhecimento circulado em Belo Monte durante a sua curta existência física no sertão baiano (1893-1897), que se atualiza, corporiza e vocaliza em tantas outras vozes e presenças, como em Maria Senhora, praticante do Reisado no Quilombo Mata de São José, localizado às margens do rio São Francisco, no sertão pernambucano. Em nosso experimento híbrido, foi possível contar com um depoimento de Senhorinha, como é mais conhecida na comunidade, nas últimas cenas de Notícias do Dilúvio (NOTÍCIAS, 2021):

Sou descendente das mulheres de Canudos que vieram fugidas da guerra e elas foram acolhidas por ex-escravos negros que fugiram e ficaram aqui no nosso Quilombo. A nossa brincadeira, da cultura da nossa comunidade, é o reisado, onde a gente junta as crianças e mulheres para poder cantar e dançar. O Reisado, pra gente, é uma forma de resistência, uma armadura de existir para resistir.

Para demonstrar o quanto Belo Monte permanece vivo em uma comunidade constituída a partir de mulheres em fuga desesperada de uma entre tantas tentativas de genocídio provocadas pelo Estado brasileiro, Senhorinha deixa o registro de uma canção que embala a celebração do Reisado em seu Quilombo (NOTÍCIAS, 2021):

Secretário, atrevido, deixa de aperrear

Ô, nem que o sangue dê no joelho

Mas eu tenho que guerrear

Eu morro, eu morro, eu morro e não me entrego

Olha a guerra, olha a guerra no mar

É essa canção que embala a última encruzilhada poética da encenação apresentada sob o tema Encruzilhada Nordeste(s): (contra)narrativas poéticas. A voz de Senhorinha é a paisagem sonora da última imagem, em que as duas personagens, Das Dores e Dos Anjos, estão sentadas em uma barca sobre as águas do Velho Chico, com a coroa e a espada do Reisado, o olhar atento e profundo, segurando, ao centro, uma fotografia emoldurada das ruínas da segunda Canudos. 
Figura 3 - Das Dores e Dos Anjos na abertura de Notícias do Dilúvio - um canto a Canudos

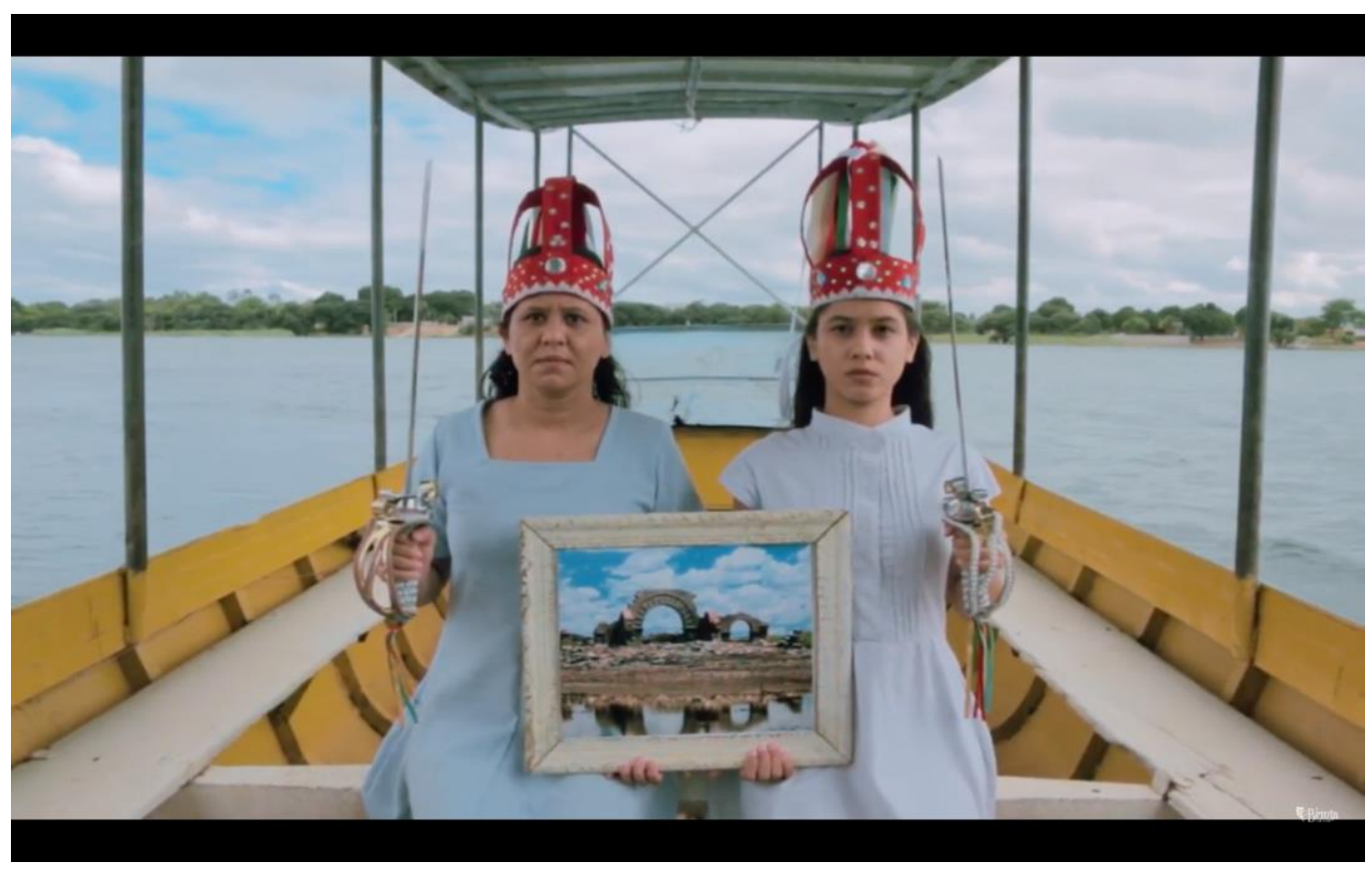

Fonte: Canal da Cia Biruta de Teatro no YouTube. Fotografia: Fernando Pereira

Soa o sino, a voz se cala, a imagem se apaga e sobem os créditos ao som de instrumentos percussivos, assobios de pássaros, movimentos de águas, passos na mata e encruzilhadas de cosmoencantamentos.

\section{Considerações finais}

Para deixar um território sagrado é preciso agradecer. É o agradecimento que traz a marca do reconhecimento pelo conhecimento que se incorpora como experiência no decorrer da caminhada. Tanto quanto pedir licença para entrar em contato com o manancial poético das performances da oralitura, das práticas culturais populares, dos referenciais teórico-metodológicos, das mestras e mestres que percorrem conosco o 
território navegante da arte e da vida, a Cia Biruta de Teatro tem agradecido em seus 13 anos de existência e resistência no sertão do São Francisco.

Nas últimas linhas deste relato de experiência, deixamos expresso o nosso agradecimento a todas as vozes que emergiram durante esta escrita. As bordaduras tecidas neste universo digital nos ajudam a refletir sobre os percursos físicos e espirituais e, ao mesmo tempo, novas paisagens se abrem no horizonte da encenação teatral. Evidentemente, algumas escolhas foram necessárias e outras possibilidades de comunicação dos nossos percursos criativos, inclusive na montagem de Notícias do Dilúvio, ficam para um próximo relato.

Entre os possíveis temas de aprofundamento da encenação, caberiam reflexões sobre a adaptação da dramaturgia da peça para um roteiro cinematográfico, a progressão da cena e os diálogos estabelecidos com a constituição e a mudança do cenário, a simbologia de cada um dos objetos cênicos que aparecem nas cenas internas e de cada paisagem percorrida nas tomadas externas, as concepções de sertão e nordeste gestadas na encenação, entre tantas outras possibilidades de abordagem do experimento híbrido debatido neste relato.

Tantas temáticas que se insurgem nas últimas linhas deste escrito só reforçam a necessidade de seguir em caminhada reflexiva e prática pelas veredas do grande sertão que conduz os nossos caminhos. A certeza que deixamos registrada é, parafraseando Pessoa (2006), da precisão de navegar, embora a vida ande tão imprecisa. Seguiremos navegando com as nossas ancestralidades e com quem cotidianamente celebra um presente de vida em abundância e constrói um futuro mais justo, digno e promissor.

A todas essas presenças, encarnadas e desencarnadas, e a vocês, que nos lêem até aqui, deixamos o nosso terno agradecimento. Modupé ${ }^{13}$ !

\section{Referências}

AKOTIRENE, Carla. O que é interseccionalidade. Coordenação Djamila Ribeiro. Belo Horizonte: Letramento, 2018.

ARRAES, Jarid. As lendas de Dandara. São Paulo: Cultura, 2016.

\footnotetext{
${ }^{13}$ Modupé ou Mo dúpẹ́ é uma palavra em Yorubá que expressa o ato de ser grata/o, de se mostrar agradecida/o a alguém.
} 
BÂ, Amadou Hampaté. A Tradição Viva. In: ISKANDER, Z. (Org.) História Geral da África. Vol. 1. São Paulo: Ática, Unesco, 1980.

BARBA. Eugenio. A arte secreta do ator: dicionário de antropologia teatral. Campinas: HUCITEC, 1995.

BARBA. Eugenio. Teatro: Solidão, Ofício e Revolta. Brasília: Teatro Caleidoscópio, 2010.

BENÍCIO, Manoel. O rei dos jagunços: crônica histórica e de costumes sertanejos sobre os acontecimentos de Canudos. Rio de Janeiro: Editora Fundação Getúlio Vargas, 1997.

CIA Biruta de Teatro. Notícias do Dilúvio - Um canto a Canudos. YouTube, 30 mai. 2021. Disponível em: <https://www.youtube.com/watch?v=3MisEbL9S6E\&t=89s>. Acesso em: 31 mai. 2021.

CUNHA, Euclides. Canudos: diário de uma expedição. São Paulo: Martin Claret, 2016.

EVARISTO, Conceição. Poemas da recordação e outros movimentos. Rio de Janeiro: Malê, 2017.

GUIMARÃES ROSA, João. Grande sertão: veredas. Rio de Janeiro: Nova Fronteira, 1986.

LALO, Eduardo. Notícias do Dilúvio. Tradução de Letícia Malloy. Suplemento

literário de Minas Gerais, Belo Horizonte-MG, ed. 1355, p. 36-39, jul./ago. 2014.

LÓPEZ, Maximiliano Valerio. O conceito de experiência em Michel Foucault. Revista Reflexão e Ação, Santa Cruz do Sul, v.19, n.2, jul./dez. 2011. Disponível em: https://online.unisc.br/seer/index.php/reflex/article/view/2367. Acesso em: 30 mai. 2021.

MARTINS, Leda. Performances da oralitura: corpo lugar da memória. Língua e Literatura: Limites e fronteiras, Santa Maria, n. 26, p. 63-81, 2003.

MONIZ, Edmundo. Canudos: a guerra social. 2.ed. Rio de Janeiro: Elo Editora, 1987.

PESSOA, Fernando. Livro do Desassossego. São Paulo: Companhia das Letras, 2006.

STUDART, Hugo. A Lei da Selva: Estratégias, Imaginário e Discurso dos Militares Sobre a Guerrilha do Araguaia. São Paulo: Geração Editorial, 2006. 